\title{
EL LÉXICO EN EL AULA DE EDUCACIÓN INFANTIL Y PRIMARIA: ENSEÑA Y APRENDE JUGANDO CON ENRÉDATE
}

\section{THE LEXICON IN THE CLASSROOM OF EARLY CHILDHOOD AND PRIMARY EDUCATION: TEACHES AND LEARNS PLAYING WITH ENRÉDATE}

\author{
Narciso M. Contreras Izquierdo \\ Universidad de Jaén \\ ncontrer@ujaen.es
}

\begin{abstract}
RESUMEN
En las primeras etapas educativas, la competencia en comunicación lingüística (CCL) se considera clave para un adecuado desarrollo cognitivo, social y educativo del alumnado, pues sirve de instrumento de mediación que posibilita la construcción del pensamiento y el acceso al conocimiento. En el desarrollo de la CCL, el léxico constituye un componente determinante, puesto que es fundamental tanto para transmitir como para comprender un mensaje. Convencidos de ello, hemos confeccionado una novedosa e innovadora herramienta lexicográfica en línea, enRÉDate, un diccionario temático por imágenes para aprender y enseñar vocabulario de un modo enactivo y lúdico, diseñado para niños de 0 a 8 años. En este trabajo ofreceremos una caracterización de dicha obra, así como la orientación para la realización una serie de actividades que hemos diseñado para su explotación didáctica en Educación Infantil y Primaria.
\end{abstract}

Palabras clave: Competencia en comunicación lingüística, competencia léxica, diccionario, Educación Infantil y Primaria

\begin{abstract}
In the early stages of education, the competence in linguistic communication (CLC) is considered key for an adequate cognitive, social and educational development of the students, since it serves as an instrument of mediation that enables the construction of thought and access to knowledge. In the development of the CLC, the lexicon constitutes a determining component, since it is fundamental both to transmit and to understand a message. Convinced of this, we have created a novel and innovative online lexicographical tool, enRÉDate, a thematic image dictionary to learn and teach vocabulary in an enactive and ludic way, designed for children from 0 to 8 years old. In this work we will offer a characterization of this dictionary, as well as the orientation for the realization of a series of activities that we have designed for its didactic exploitation in Early Childhood and Primary Education.
\end{abstract}

Keywords: Competence in linguistic communication, lexical competence, dictionary, Early Childhood and Primary Education 


\section{INT'RODUCCIÓN}

La competencia en comunicación lingüística (CCL) en las primeras etapas educativas, Educación Infantil y Primaria, es clave para un adecuado desarrollo cognitivo, social y educativo del alumnado, pues el lenguaje constituye, además del instrumento para la comunicación oral y escrita, una herramienta de representación, interpretación y comprensión de la realidad, de construcción y comunicación del conocimiento y de organización y autorregulación del pensamiento, las emociones y la conducta.

La lengua, en sus modalidades oral y escrita, está presente en la inmensa mayoría de las actividades humanas, entre ellas, la educación. En este ámbito, la competencia lingüística desempeña un papel esencial, pues sirve de instrumento de mediación que posibilita la construcción del pensamiento y el acceso al conocimiento en todas las áreas curriculares por parte de los aprendices.

El profesorado de estas etapas debe tomar consciencia de la enorme trascendencia que esto tiene para los alumnos desde la infancia, pues el dominio de la lengua propiciará su enriquecimiento intelectual, serán capaces de establecer comunicaciones fluidas y adecuadas con los demás miembros de su comunidad. Igualmente, al ser capaces de entender tanto el sentido evidente de los mensajes como sus matices y sus diversas interpretaciones, formarán un pensamiento crítico, pudiendo así decidir mejor por sí mismos. Además, quien utiliza su lengua de forma adecuada podrá tener, con toda seguridad, mayores oportunidades de éxito laboral, así como proyectar una imagen positiva ante los demás.

Para dicho desarrollo de la CCL, la competencia léxica se erige en un componente determinante, puesto que tanto para transmitir como para comprender un mensaje el léxico es imprescindible. Tanto es así, que Wilkins (1972) afirmaba que "sin gramática poco se puede comunicar, sin léxico nada".

En este sentido, el diccionario representa una herramienta óptima para la ampliación de la competencia léxica y, por tanto, de la competencia comunicativa del alumno. Convencidos de ello, y del carácter central del léxico en la CCL, hemos confeccionado una novedosa e innovadora herramienta lexicográfica, enRÉDate (Moreno, Contreras, Torres, Camacho y Ruiz, 2018), un diccionario por imágenes 
organizado temáticamente para aprender vocabulario de un modo lúdico, diseñado para niños de 0 a 8 años. Sobre esta base, el objetivo de este trabajo será realizar una presentación de dicha obra y ofrecer una serie de actividades para orientar su explotación didáctica en Educación Infantil y Primaria.

\section{EL COMPONENT'E LÉXICO EN LA CCL}

El enfoque competencial ha cobrado una especial relevancia en los últimos años en el currículo de los primeros estadios educativos, estableciéndose una serie de competencias básicas o "clave" que deben desarrollarse en todas las áreas curriculares ${ }^{1}$. Las competencias básicas establecidas por los Reales Decretos de enseñanzas mínimas incluyen, en primer lugar, la competencia en comunicación lingüística (CCL).

Por lo que respecta a dicha competencia en el currículo correspondiente a la Educación Infantil, en el área de "Lenguajes: comunicación y representación” se señala:

Esta área de conocimiento y experiencia pretende desarrollar en niños y niñas las capacidades comunicativas aprendiendo a utilizar, de forma cada vez más adecuada, las distintas formas de comunicación y representación corporal, gestual, verbal —oral y escrita—, artística —plástica y musical-, audiovisual y tecnológica, ayudando así a mejorar el conocimiento y las relaciones del niño y la niña con el medio. Estas formas de comunicación y representación sirven de nexo entre el mundo exterior e interior al ser instrumentos simbólicos que hacen posible la representación de la realidad, la expresión de pensamientos, sentimientos, vivencias, la regulación de la propia conducta y las interacciones con los demás (BOJA 169, 2008: 37)

Además, entre los objetivos (BOJA 169, 2008: 38), se incluye "utilizar el lenguaje oral como instrumento de comunicación, de representación, aprendizaje y disfrute, de expresión de ideas y sentimientos, valorándolo como un medio de relación con los demás y de regulación de la convivencia”.

Por lo que respecta al Currículo de Educación Primaria, se indica lo siguiente sobre la CCL:

\footnotetext{
${ }^{1}$ El Parlamento Europeo y el Consejo de Europa (2005) definen estas competencias clave como "combinación de conocimientos, capacidades y actitudes adecuadas al contexto. Las competencias clave son aquellas que todas las personas precisan para su realización y desarrollo personal, así como para la ciudadanía activa, la inclusión social y el empleo. Al término de la educación y la formación iniciales, los jóvenes deben haber desarrollado las competencias clave en la medida necesaria para prepararlo para la vida adulta y deben seguir desarrollándolas, manteniéndolas y poniéndolas al día en el contexto del aprendizaje permanente".
} 


\section{EL LÉXICO EN EL AULA DE EDUCACIÓN INFANTIL Y PRIMARIA: \\ ENSEÑA Y APRENDE JUGANDO CON ENRÉDATE \\ Narciso M. Contreras Izquierdo}

La competencia en comunicación lingüística es también un instrumento fundamental para la socialización y el aprovechamiento de la experiencia educativa, por ser una vía privilegiada de acceso al conocimiento dentro y fuera de la escuela [...]. La competencia en comunicación lingüística se inscribe en un marco de actitudes y valores que el individuo pone en funcionamiento: el respeto a las normas de convivencia; el ejercicio activo de la ciudadanía; el desarrollo de un espíritu crítico; el respeto a los derechos humanos y el pluralismo; la concepción del diálogo como herramienta primordial para la convivencia, la resolución de conflictos y el desarrollo de las capacidades afectivas en todos los ámbitos; una actitud de curiosidad, interés y creatividad hacia el aprendizaje y el reconocimiento de las destrezas inherentes a esta competencia (lectura, conversación, escritura, etcétera) como fuentes de placer relacionada con el disfrute personal y cuya promoción y práctica son tareas esenciales en el refuerzo de la motivación hacia el aprendizaje (BOE, 25. 29/01/2015: 6991 y ss.).

Como hemos adelantado, y comprobamos en el marco normativo, se entiende la CCL como básica para el desarrollo personal y social del individuo, así como para el acceso al conocimiento.

Desde un punto de vista comunicativo, el componente léxico desempeña un papel cardinal en esta competencia, puesto que aunque no se domine del todo la gramática, es posible comunicarse mediante las palabras clave ${ }^{2}$. Y no solo esto, sino que como señala Moreno Ramos (2004: 164), "si ampliamos el bagaje léxico de los escolares les posibilita que puedan comunicarse con mayor precisión, propiedad y claridad, al tiempo que favorecemos procesos mentales tan importantes como ordenar, relacionar, matizar y clasificar la realidad individual y extrapersonal".

Para este aprendizaje, se hace necesario implementar una metodología adecuada y coherente con estos principios, y así, las nuevas teorías proponen un modelo lexicológico y lexicográfico basado en el concepto de "lexicón":

Llamamos "lexicón" a la parte de la competencia lingüística que contiene las piezas léxicas o formantes, es decir, las raíces y temas, los afijos flexivos y derivativos, y las reglas que regulan su combinación. El concepto es cognitivo, dinámico, procesual, a diferencia del concepto de "léxico", como sinónimo de "vocabulario", entendido como un simple listado de palabras, o

\footnotetext{
2 Para conocer más sobre el desarrollo y el papel del lexicón en las fases tempranas de la comunicación verbal, véase Guibourg (2008: 32-29): las primeras son denominadas "palabras frase" u "holofrase" (entre los 12 y los 18 meses), que tienen más un valor de señal, de gesto comunicativo, y que adquieren sentido en el contexto compartido. Hasta el segundo año, el léxico se va incrementando lentamente, pero a partir de ese momento aumenta rápidamente por la necesidad de comunicarse en contextos significativos. En esta fase, el niño incorpora palabras con un valor referencial para denotar lo que antes hacía con gestos. Entre los tres y los cinco años, el aumento constante del léxico le permite expresarse con mayor precisión, aumentando su placer por hablar y dialogar. Es por esto por lo que estimamos que enRÉDate puede contribuir decisivamente al incremento del lexicón infantil, no solo a partir del inicio de la escolarización, sino incluso previamente, como apoyo a los padres en el hogar.
} 


\section{EL LÉXICO EN EL AULA DE EDUCACIÓN INFANTIL Y PRIMARIA: \\ ENSEÑA Y APRENDE JUGANDO CON ENRÉDATE \\ Narciso M. Contreras Izquierdo}

como una organización de campos semánticos. El lexicón es un constructo que da cuenta de la capacidad creativa del lenguaje, y por lo tanto de las lenguas. Permite comprender y explicar los fenómenos de generación de nuevas palabras, que pueden ser entendidas, procesadas y recreadas de manera novedosa, sin información explícita, por cualquier hablante nativo e, inclusive, por un hablante no nativo de una lengua (Baralo, 2001: 12) ${ }^{3}$.

Las recientes investigaciones sobre este tema concluyen que las palabras se almacenan en el lexicón no como en un diccionario, sino formando redes, con relaciones de diversa tipología, que se van ampliando a lo largo del tiempo, conforme se produce una exposición paulatina al imput (Higueras, 2004: 13).

Así, desde un punto de vista cognitivo, nuestra mente estructura y organiza la realidad precisamente a través de las unidades léxicas, y dicha estructuración podemos concebirla como una inmensa red en la que dichas unidades forman conexiones, se unen unas a otras a través de semejanzas, dependencias y oposiciones ${ }^{4}$.

Es por esto por lo que, en el aula, debemos enseñar el vocabulario de forma que nuestros alumnos sean capaces de integrar las palabras en una red que las enlace, que les aporte sentido, agrupándolas mediante estas relaciones para que al estudiante le resulte más sencillo memorizarlas. De otro modo, apenas retendrán unas pocas.

Las características más destacables de este lexicón mental son las siguientes (Thornbury, 2002: 17):

1. Está organizado, lo que posibilita un rápido reconocimiento y uso de las unidades léxicas.

2. Las unidades que lo forman se relacionan mediante asociaciones de todo tipo, tanto lingüísticas (fónicas, gráficas, morfológicas, semánticas, discursivas) como no lingüísticas (imágenes visuales, auditivas, conocimiento del mundo, conocimientos culturales...).

\footnotetext{
${ }^{3}$ Baralo se refiere al lexicón no nativo, pero entiende, al igual que otros investigadores que este no presenta diferencias apreciables con el de los hablantes nativos. Para conocer más sobre este tema véanse, entre otros, los trabajos de Aitchison (1994), Baralo (1997, 2001, 2005, 2006, 2007), Cervero y Pichardo (2000), Lahuerta y Pujol (1996).

${ }^{4}$ El término "red" no se emplea en sentido metafórico, ya que neuronalmente esa es su estructura. Como señalan López García et al. (2011: 65), la neurología está confirmando que los hechos del lenguaje se construyen mediante redes neuronales sinápticas. Recomendamos la lectura de dicho trabajo para conocer cómo funcionan esas redes cerebrales y su relación con la lengua.
} 
3. Igualmente, la información de cada unidad léxica es de carácter tanto lingüístico como personal (información y relaciones subjetivas formadas sobre las experiencias vitales de los hablantes).

4. Dicha información de una unidad léxica en el lexicón mental no supone necesariamente un conocimiento "completo" (fonología, ortografía, significado, construcción, etc.) ni "correcto", ya que el conocimiento de una unidad por parte de un individuo puede diferir del propio de esa unidad léxica en su comunidad de habla, o incluso puede ser considerado inadecuado o erróneo por otros miembros de su comunidad.

5. Es por esto por lo que el conocimiento sobre las unidades es incrementable: la cantidad de ocasiones en que se oye o lee una unidad, entre otros factores, contribuye a ampliar la información disponible por los hablantes.

De lo dicho se desprende que, para conocer una palabra, es necesario atender a distintas dimensiones (forma, significado y uso). Nation (2001: 27) recoge todo el volumen de información que ello implica (Tabla 1):

\begin{tabular}{|c|c|c|c|}
\hline \multirow[t]{6}{*}{ Forma } & \multirow[t]{2}{*}{ Hablada } & $\mathrm{R}$ & ¿Cómo suena la palabra? \\
\hline & & $\mathrm{P}$ & ¿Cómo se pronuncia? \\
\hline & \multirow[t]{2}{*}{ Escrita } & $\mathrm{R}$ & $\begin{array}{l}\text { ¿Cómo reconocemos esta palabra en la escritu- } \\
\text { ra? }\end{array}$ \\
\hline & & $\mathrm{P}$ & ¿Cómo se escribe y deletrea? \\
\hline & \multirow[t]{2}{*}{ Partes de la palabra } & $\mathrm{R}$ & ¿Qué partes se pueden reconocer en la palabra? \\
\hline & & $\mathrm{P}$ & $\begin{array}{l}\text { ¿Qué partes se necesitan para expresar el signi- } \\
\text { ficado? }\end{array}$ \\
\hline \multirow[t]{6}{*}{ Significado } & \multirow[t]{2}{*}{ Forma y significado } & $\mathrm{R}$ & ¿Qué significado tiene esta palabra? \\
\hline & & $\mathrm{P}$ & $\begin{array}{l}\text { ¿Qué palabra puede usarse para expresar ese } \\
\text { significado? }\end{array}$ \\
\hline & \multirow[t]{2}{*}{ Concepto y referentes } & $\mathrm{R}$ & $\begin{array}{l}\text { ¿Qué se incluye en el concepto al que la palabra } \\
\text { se refiere? }\end{array}$ \\
\hline & & $\mathrm{P}$ & ¿A qué puede referirse el concepto? \\
\hline & \multirow[t]{2}{*}{ Asociaciones } & $\mathrm{R}$ & ¿En qué otras palabras nos hace pensar? \\
\hline & & $\mathrm{P}$ & $\begin{array}{l}\text { ¿Qué otras palabras podríamos usar en lugar de } \\
\text { esta? }\end{array}$ \\
\hline \multirow[t]{6}{*}{ Uso } & \multirow[t]{2}{*}{ Función gramatical } & $\mathrm{R}$ & $\begin{array}{l}\text { ¿En qué esquemas sintácticos y semánticos apa- } \\
\text { rece esta palabra? }\end{array}$ \\
\hline & & $\mathrm{P}$ & $\begin{array}{l}\text { ¿En qué esquemas sintácticos y semánticos po- } \\
\text { demos usar esta palabra? }\end{array}$ \\
\hline & \multirow[t]{2}{*}{ Colocaciones } & $\mathrm{R}$ & $\begin{array}{l}\text { ¿Qué palabras o tipos de palabras aparecen con } \\
\text { esta palabra? }\end{array}$ \\
\hline & & $\mathrm{P}$ & $\begin{array}{l}\text { ¿Qué palabras o tipos de palabras tenemos que } \\
\text { usar con esta palabra? }\end{array}$ \\
\hline & \multirow[t]{2}{*}{$\begin{array}{l}\text { Restricciones de uso } \\
\text { (registro, frecuencia...) }\end{array}$} & $\mathrm{R}$ & $\begin{array}{l}\text { ¿Dónde, cuándo y con qué frecuencia espera- } \\
\text { ríamos que apareciera esta palabra? }\end{array}$ \\
\hline & & $\mathrm{P}$ & $\begin{array}{l}\text { ¿Dónde, cuándo y con qué frecuencia podemos } \\
\text { usar esta palabra? }\end{array}$ \\
\hline
\end{tabular}

( $\mathrm{R}=$ conocimiento receptivo $/ \mathrm{P}=$ conocimiento productivo $)$

TABLA 1. ¿Qué implica saber una palabra? Nation (2001:27) 
Por tanto, para un adecuado uso de una unidad léxica, es necesario dotar a los estudiantes de una amplia gama de conocimientos sobre pronunciación y ortografía (conocer los sonidos y los fonemas que la forman, saber reconocerla oralmente y poder pronunciarla, conocer sus letras, saber descifrarla y escribirla), morfología (género, número, persona, tiempo, sufijos, prefijos, palabras compuestas, palabras relacionadas formalmente con ella, etc.), sintaxis (saber usarla en contexto, conocer la categoría, las subcategorizaciones, los regímenes verbales, etc. y todas las reglas que regulan su uso sintáctico), semántica (conocer sus diversas acepciones, usos figurados, su valor semántico según el contexto lingüístico, su significado denotativo y su valor connotativo, relacionarla con un concepto asociado a un elemento real, relacionarla semánticamente con otras unidades léxicas), pragmática (emplearla como parte de un texto en relación con un contexto para conseguir un propósito determinado) y sociolingüística (conocer su valor dialectal y de registro, utilizarla de forma adecuada a la situación comunicativa) (Cassany et al., 2003: 380).

Todo lo dicho repercute en el tratamiento didáctico de este componente lingüístico. En primer lugar, basándonos en el carácter dinámico e incrementable de la información contenida en el lexicón, debemos exponer a los aprendientes a diferentes aductos que proporcionen información variada que contribuya a ampliar el conocimiento que se tiene sobre las distintas unidades. En segundo lugar, el hecho de que el lexicón esté organizado y la evidencia de que las distintas unidades establecen múltiples relaciones entre sí, debe orientar al empleo de actividades asociativas para la enseñanza y aprendizaje del léxico, mediante, por ejemplo, mapas de ideas, redes, asociogramas, etc.

Además, debemos ser conscientes de que el conocimiento nuevo es más fácilmente absorbido cuando está relacionado con algo ya conocido, activándose en el alumno el marco de conocimiento adecuado (McCarthy, 1990). Por tanto, los profesores deberíamos enseñar las unidades léxicas empleando técnicas que permitan relacionar unas con otras, pues así se almacenan en el lexicón mental, mejorando y agilizando de este modo su aprendizaje. Baralo (2001: 37) apunta algunas orientaciones didácticas para ello: 


\section{EL LÉXICO EN EL AULA DE EDUCACIÓN INFANTIL Y PRIMARIA: \\ ENSEÑA Y APRENDE JUGANDO CON ENRÉDATE \\ Narciso M. Contreras Izquierdo}

En general, se podría sintetizar en dos aspectos: por un lado, las fuentes, que deberán presentar un input comprensible, sujeto a la regla de Krashen $(i+1)$, a través de la interacción oral, las lecturas variadas, las audiciones y los visionados de situaciones de comunicación y de actos de habla comprensibles. Por otro, las actividades deberían favorecer las estrategias de asociación de piezas léxicas, a través de sus redes, como las asociaciones morfológicas (derivación y composición); semánticas (hiponimia e hiperonimia; sinonimia y antonimia; polisemia; campos semánticos y asociativos); léxicas (cognados, expresiones idiomáticas); discursivas (conectores textuales, según los géneros) y pragmáticas (selección léxica condicionada por las variables de la situación de comunicación).

Con todo esto, es evidente que la práctica expresa del léxico resulta imprescindible en el desarrollo de la competencia comunicativa del alumno, con el objetivo de que este sea capaz tanto de comprender como de utilizar las palabras en diversas situaciones como respuesta a una necesidad concreta relacionada con un tipo de texto o con un área temática determinada.

\section{EL DICCIONARIO COMO HERRAMIENTA PARA LA ENSEÑANZA Y EL APRENDIZAJE}

Como hemos adelantado, el diccionario, herramienta de aprendizaje autónomo del léxico por excelencia, constituye un elemento esencial en la adquisición de vocabulario, aunque su potencial didáctico va mucho más allá, pues su empleo en el aula posibilita el desarrollo de la capacidad oral y escrita del alumnado, y trascendiendo lo puramente lingüístico, contribuye igualmente al desarrollo del autoconocimiento y de la autonomía personal, así como al conocimiento del entorno.

Por tanto, es necesario que los alumnos conozcan las posibilidades que el diccionario ofrece incluso desde el inicio de su formación ${ }^{5}$. Es por esto por lo que esta obra debería estar siempre presente en el aula, tanto en las clases de lengua como en

\footnotetext{
${ }^{5}$ Cassany et al. (2003: 385-6) recogen los objetivos didácticos específicos en cuanto al conocimiento y uso del diccionario: i. Conocer los diversos tipos de diccionarios (generales, enciclopédicos, bilingües, de sinónimos, ideológicos, etc.); ii. Conocer la estructura del diccionario (ordenación, estructura de una entrada, informaciones que contiene, ejemplos, etc.); iii. Saber interpretar la información semántica y gramatical que proporcionan las entradas de los diccionarios; iv. Comprender las definiciones y los ejemplos y saber elaborarlos. Estos mismos autores llaman la atención sobre la responsabilidad del profesor de saber elegir el diccionario adecuado para cada situación y necesidad concreta. Como señala Prado (2005b: 19), "la instrucción en el uso del diccionario desde los primeros años de escolaridad es fundamental, pues sólo así se desarrollará el hábito de su consulta”.
} 
las de las demás materias ${ }^{6}$, suscribiendo la opinión de Alvar Ezquerra (1993: 165): “El diccionario se considera un instrumento didáctico fundamental para que el alumno pueda mejorar el aprendizaje de la lengua de manera más completa, sobre todo por lo que se refiere al aprendizaje del léxico, y no solo con el uso de los manuales de gramática”.

Sin embargo, y por desgracia, en el nivel educativo de Infantil y Primaria parece existir un desconocimiento generalizado de sus posibles aplicaciones en el aula, ya que en la mayoría de los currículos de Educación no se incluyen asignaturas o contenidos sobre lexicografía. Por tanto, deberíamos comenzar por instruir a los futuros maestros en la integración de esta herramienta en su metodología docente para la enseñanza de la lengua materna.

En primer lugar, los docentes deben tener conocimientos básicos sobre las distintas clases de obras lexicográficas, puesto que en los niveles iniciales resultaría inapropiado comenzar con diccionarios convencionales, ya que, como bien señala Prado (2000: 174) "es evidente que no todos los diccionarios son iguales ni sirven para obtener la misma información y no todos los diccionarios son adecuados para todo el mundo"”. En consecuencia, el profesor debe adiestrar a los alumnos en su manejo, conociendo y señalando las ventajas e inconvenientes de unos y de otros, guiando así al alumno entre el gran número de obras y tipologías existentes.

En estos primeros niveles educativos debemos utilizar el denominado "diccionario infantil" o "diccionario para niños", obras confeccionadas para estudiantes de 0 a 6 años durante el aprendizaje de la lectura, y que son distintos de los "diccionarios escolares", para una etapa más avanzada de aprendizaje (entre 6 y 11 años) en la que ya pueden leer'.

\footnotetext{
${ }^{6}$ Incluso ya en el RD 126/2014 de 28 de febrero por el que se establece el currículo básico de la Educación Primaria (BOE, n. ${ }^{\circ}$ 52), en el bloque 4 ("conocimiento de la lengua") del apartado de contenidos se recomienda el "uso eficaz del diccionario para ampliación de vocabulario y como consulta ortográfica".

${ }^{7}$ Para conocer más sobre el valor didáctico del diccionario y sobre las necesidades formativas del profesorado, véanse, entre otros, Alvar Ezquerra (1993, 2001, 2003) y Prado Aragonés (2000, 2005b).

${ }^{8}$ Para una reseña histórica de esta tipología, véase Moreno (2016b).

${ }^{9}$ No obstante, en el ámbito español la denominación "diccionario escolar" se emplea en un sentido amplio, englobando ambas tipologías, refiriéndose así al diccionario monolingüe que se usa en el centro
} 


\section{EL LÉXICO EN EL AULA DE EDUCACIÓN INFANTIL Y PRIMARIA: \\ ENSEÑA Y APRENDE JUGANDO CON ENRÉDATE \\ Narciso M. Contreras Izquierdo}

Por lo que se refiere a las características propias de los infantiles, estos han dispuesto tradicionalmente sus materiales según una estructura temática, mediante campos conceptuales, esto es, siguiendo una organización onomasiológica, debido a que

No cabe duda de que dicho formato se presenta como el más apropiado para la aproximación del léxico en la edad infantil, puesto que comparte el modelo de adquisición: conceptualización lingüística y clasificación lógica y general de la lengua. Nadie aprende una lengua por orden alfabético, de ahí que la estructura semasiológica no sea la adecuada para aquellos aprendientes que no han desarrollado la lectoescritura y no conciben el orden por abc (Moreno, 2016a: 234).

Así, esta obra puede y debe convertirse en una herramienta útil de descripción y conocimiento lingüístico, así como para el desarrollo de competencias clave del alumnado de estas etapas formativas.

\section{ENRÉD ATE ${ }^{10}$ : CARACTERIZACIÓN, ESTRUCTURACIÓN Y CONTENIDOS}

La obra que presentamos aquí es un diccionario por imágenes organizado temáticamente para aprender vocabulario, diseñado para niños de 0 a 8 años $^{11}$, y basado en diversos presupuestos básicos, como son la perspectiva enactiva, el métodoaudiovisual, la competencia digital y el componente lúdico.

EnRÉDate toma como base una fundamentación enactiva ${ }^{12}$, pues como señala Gesú (2016: 59), la construcción del lexicón mental es el resultado de la interacción entre el mundo mental y el mundo social, proceso que se produce por la enactuación simultánea de la cognición y el medio ambiente. Esto significa que la adquisición del lenguaje en la etapa infantil no se produce mediante una imitación pasiva, sino por un

escolar para el aprendizaje de la lengua materna indistintamente del nivel educativo (Moreno, 2016a: 235).

${ }^{10}$ Para conocer el desarrollo de este proyecto, así como una caracterización más específica de la obra, véase Moreno (2016a). Igualmente, en el trabajo de Camacho Niño en esta misma obra ("Estructuras textuales y lexicográficas en EnRÉDate. Diccionario temático infantil') se presenta una completa caracterización desde la teoría funcional de la lexicografía, y se determinan y explican aspectos fundamentales como los usuarios potenciales, sus necesidades, las situaciones de uso y sus funciones.

${ }^{11}$ Aunque este es el público meta para el que ha sido diseñado, los contenidos de esta obra también pueden emplearse para la enseñanza del español como lengua extranjera (ELE), tal y como muestra Torres Martínez en esta misma obra ("enRÉDate. Diccionario temático infantil, herramienta en el aula de ELE").

${ }^{12}$ Para conocer más sobre esta fundamentación enactiva en el diccionario, véase el trabajo de Moreno Moreno (“Aprendizaje rizomático y perspectiva enactiva en EnRÉDate. Diccionario temático infantil”) en esta misma publicación. 
proceso interactivo entre la cognición y el ambiente que nos rodea, y que produce una experiencia cognitiva biológica (corporizada), psicológica y cultural $^{13}$.

Teniendo siempre presente el público al que va dirigido, alumnos de corta edad, se estima que es adecuado el empleo del método audio-visual para el desarrollo de la competencia léxica ${ }^{14}$, ya que "lo que estimula la reacción emocional para la comprensión, es la imagen asociada con palabras en nuestra mente" (Arnold, 2000: 281). De este modo, imagen y sonido se asocian al texto para potenciar la comprensión y memorización de sonido, grafía e imagen, uniendo las palabras con las cosas (Moreno, 2016a: 237-238).

Para este público infantil, esta obra representa un espacio lúdico de aprendizaje digital que permite tanto el uso doméstico individual (como un medio de diversión, entretenimiento y/o ayuda a las tareas escolares), como el uso compartido en el centro escolar, siendo en este último contexto donde este recurso se muestra en su máxima extensión, ya que se presenta como una aplicación docente nueva, por su estructura y aplicación, que el profesor pueda emplear para fomentar el desarrollo de la competencia léxica de sus alumnos, así como otras competencias claves como son la de aprender a aprender, la autonomía e iniciativa personal y el tratamiento de la información y competencia digital.

En cuanto a esta última competencia, es evidente que la tecnología está provocando un replanteamiento del proceso educativo, de ahí que debamos aprovechar las ventajas que las tecnologías de la información y de la comunicación (TIC) aportan como apoyo

\footnotetext{
${ }^{13}$ Para potenciar esta experiencia cognitiva corporizada, hemos diseñado una amplia serie de actividades que propician la imitación interactiva en un entorno de aprendizaje digital. Igualmente, la cognición social y cultural está muy presente en el diccionario a través de enlaces a Google imagénes y a la Wikipedia, así como a canciones, cuentos, adivinanzas...

${ }^{14}$ Este método se basa en la "teoría del código dual" (Dual Coding Theory, DCT, Clark y Paivio, 1991; Paivio, 2014): la asociación de la información verbal con un estímulo no verbal ayuda a fijar la unidad léxica, y también a recuperarla. Cuando se ofrece al alumno la información en dos formatos (palabras e imágenes), estamos posibilitando dos vías para que pueda recordar la información más tarde. De este modo, combinar lo visual con lo verbal es una manera efectiva de estudiar (Meyer y Anderson, 1992). Tanto es así que, desde la DCT, se considera que la vinculación de la mente verbal y no verbal constituye el motor esencial de nuestro intelecto. Igualmente, desde el ámbito de los estudios cognitivos (Botta, 2012), investigaciones recientes confirman que los estímulos que combinan modalidades sensoriales diferentes (por ejemplo, la visual y auditiva) parecen captar la atención mejor que los estímulos por separado, y así consiguen fijarse en la memoria de forma más efectiva. Esto provoca un beneficio en su recuerdo posterior, lo que tiene implicaciones en muchos contextos, como el de la educación.
} 
en el currículo de enseñanza y aprendizaje de la lengua materna, ya que permiten el acceso a una amplia tipología de herramientas digitales para la práctica y el desarrollo de las destrezas lingüísticas ${ }^{15}$.

Por lo que se refiere a su estructuración, enRÉDate ha sido diseñado partiendo de las áreas temáticas que se establecen como propias para las enseñanzas mínimas de primer y segundo ciclo de Educación infantil, áreas que constituyen núcleos conceptuales o temas próximos a los intereses y a la realidad cotidiana de niños de estas edades ${ }^{16}$, que se recogen en el árbol temático del inicio de la obra, y que reproducimos a continuación (Imagen 1).

Estimamos que dicha estructuración es la más apropiada para la aproximación al vocabulario en esta etapa educativa, puesto que está en consonancia con el modelo de adquisición del léxico y la estructuración del lexicón mental, esto es, la conceptualización lingüística y la clasificación lógica y general de la lengua. Frente a esto, la estructura alfabética no es aquí la adecuada, puesto que nadie aprende una lengua por orden alfabético, además del hecho de que los aprendientes todavía no han desarrollado la lectoescritura.

${ }^{15}$ Las TIC están revolucionando el proceso de enseñanza y aprendizaje de lenguas debido a sus conocidas ventajas: motivan al alumnado, promueven un aprendizaje activo, autónomo y en colaboración, en relación con lo que se denomina "aprendizaje ubicuo" (Johnson et al., 2015: 38-39) y "aprendizaje rizomático" (Cabero y Llorente, 2015: 190-191), esto es, un aprendizaje que no ocurre solo en el aula, sino también en el hogar, en el lugar de juego, en el museo, en el parque, en las interacciones diarias que establecemos con los demás. Así, este nuevo modelo de aprendizaje no es lineal, sino ramificado ("rizomático"), empleando una gran variedad de medios no homogéneos. En el ámbito de la educación en general se habla de "pedagogía emergente", que consiste en "el conjunto de enfoques e ideas pedagógicas, todavía no bien sistematizadas, que surgen alrededor del uso de la TIC en educación y que intentan aprovechar todo su potencial comunicativo, informacional, colaborativo, interactivo, creativo e innovador en el marco de una nueva cultura del aprendizaje" (Adell y Castañeda, 2012: 15). Esto propicia el aprendizaje móvil y la pedagogía inversa o Flipped Classroom (Pérez Tornero, 2014), modelo pedagógico que propicia el trabajo de determinados contenidos y procesos de aprendizaje fuera del aula y utiliza el tiempo de clase para potenciar otros procesos de adquisición y práctica de conocimientos dentro del aula. Es por esto por lo que actualmente se aprecia un cambio en la denominación, extendiéndose la de "tecnologías del aprendizaje y conocimiento" (TAC), que se refiere tanto a la variedad de tecnologías con las que puede trabajar el profesorado como a las competencias que alumnos y docentes han de tener para convertirse en agentes del cambio social y educativo (RománMendoza, 2018: 12).

${ }^{16} \mathrm{El}$ diccionario ofrece una estructura de 18 áreas temáticas: 1. Los alimentos; 2. El cuerpo humano; 3. El vestido; 4. Las plantas; 5 . El reloj, el calendario y las estaciones; 6. Los animales; 7. Un día de campo; 8. La familia; 9. La casa; 10. El colegio; 11. Salud e higiene; 12. Juegos, deporte y diversión; 13. La calle y el barrio; 14. Los vehículos; 15. Comprar y vender; 16. Conceptos y contrastes; 17. Medios de comunicación; 18. El trabajo y los oficios. 


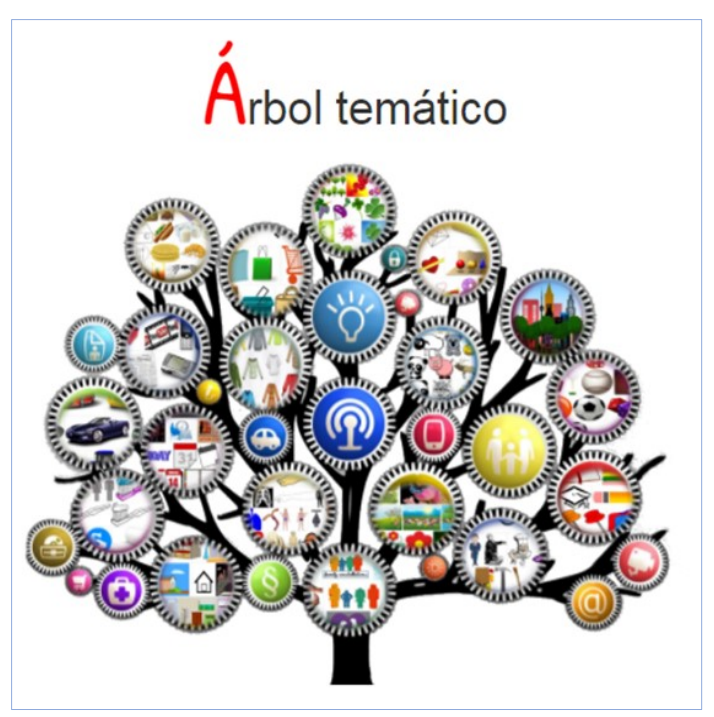

IMAGEN 1. Árbol temático

No obstante, también se ha considerado oportuno incluir un glosario de palabras organizado alfabéticamente (Imagen 2) para que los alumnos vayan familiarizándose con este orden, cuyo dominio les resultará imprescindible para la consulta de otros diccionarios en etapas posteriores. Además, esto también favorece el desarrollo de la lectoescritura.

\begin{tabular}{|c|c|c|c|c|c|}
\hline \multicolumn{5}{|c|}{ EnREDate } & (2) \\
\hline A & B & C & $D$ & $E$ & $F$ \\
\hline$G$ & $H$ & I & $\mathrm{J}$ & K & L \\
\hline$M$ & $\mathrm{~N}$ & $\tilde{N}$ & 0 & $P$ & $Q$ \\
\hline$R$ & $S$ & $T$ & U & V & $W$ \\
\hline$x$ & $Y$ & $z$ & & & \\
\hline
\end{tabular}

Igualmente, este es el motivo por el que la obra incluye mapas conceptuales básicos como estrategia de aprendizaje cognitiva (Imagen 3), y que sirven para fortalecer e incentivar la manejabilidad del léxico y la agilidad mental. Además, dichos mapas son interactivos, es decir, que cada lema es un enlace activo al campo o subcampo denominado. 


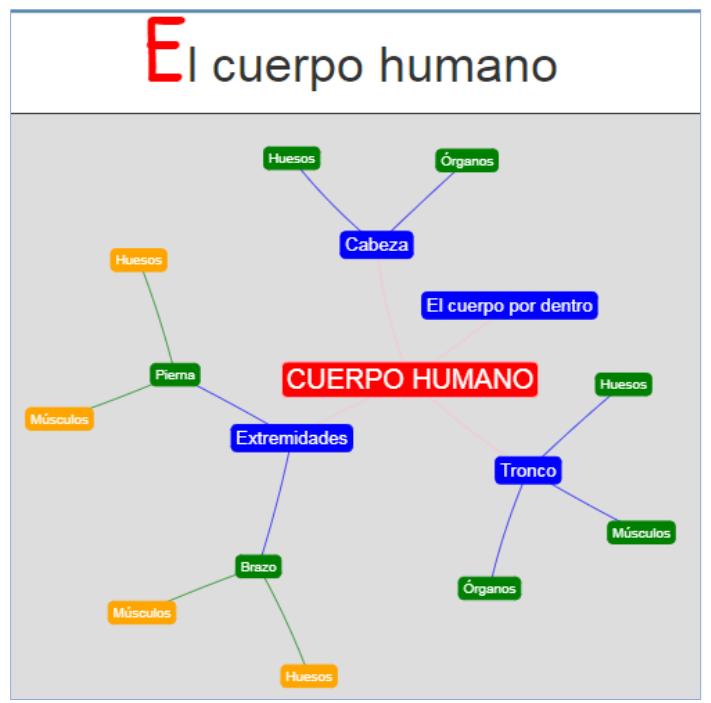

IMAGEN 3. Mapa conceptual. El cuerpo humano

Este recurso permite al docente contextualizar las unidades léxicas dentro de un espacio significativo, y al trabajar con estas redes conceptuales el estudiante toma consciencia de la relación de las palabras entre sí.

Por lo que se refiere a la selección léxica, del total de las voces recogidas, unas 2800 , entre el $80 \%$ y el 90\% son voces extraídas del léxico de los niños de segundo ciclo de infantil mediante la metodología del léxico disponible de estos estudiantes. Por otra parte, entre el 10\% y el 20\% han sido incorporadas por considerarse propias del vocabulario fundamental.

El diccionario presenta un diseño instructivo de materiales para un entorno virtual monitorizado por el ordenador, promoviendo el trabajo autónomo, lo que se consigue mediante una navegación muy sencilla, casi intuitiva, en donde se combina la palabra, la imagen y el sonido, recursos con los que los niños aprenden a la vez que juegan.

Este diseño también ofrece una consulta por capas informativas, de modo que el usuario puede dejarse llevar por los distintos campos léxicos o servirse de la información en la que esté puntualmente interesado. Igualmente, su diseño permite ofrecer material multimedia (imágenes, vídeos, audios...) que proporciona información lingüístico-cultural y motiva el aprendizaje, con secciones como "¿Sabías qué?”, "Expresiones”, “Aprendo con los cuentos” y “Aprendo con las canciones”. 
En cuanto a la microestructura de cada artículo, está condicionada por el formato digital del diccionario, así como por el método audio-visual, y muy especialmente, por su clasificación onomasiológica, ya que al no ofrecer información mediante una definición, citas u ejemplos, la descripción se da dentro del campo temático. De este modo, las palabras están interrelacionadas por afinidad semántica.

La disposición gráfica de los artículos es sencilla e intuitiva, y contiene los elementos que mostramos a continuación (Imagen 4):

1. Barra con diversos enlaces:

- Enlace al árbol temático

- Enlace al inicio del campo temático

- Enlace a mapas conceptuales

- Enlace al listado alfabético

- Flechas de avance o retroceso

- Guía de usuario/créditos/agradecimientos

- Ruta de categorización de la entrada (“Árbol temático / Los alimentos / Pirámide alimentaria / Lácteos / Vaca") ${ }^{17}$.

- Herramienta de búsqueda

2. Grafía y sonido

3. Imagen

4. Enlaces a imágenes de Google y a la entrada correspondiente de la Wikipedia

5. Enlaces a contenidos enciclopédicos como canciones, vídeos, adivinanzas...

6. Enlaces a palabras relacionadas por proximidad semántica

7. Enlace al glosario alfabético

\footnotetext{
${ }^{17}$ Esta ruta, una etiqueta digital hiperonímica, constituye la indicación semántica elemental, y permite al usuario ubicar adecuadamente la información semántica. No obstante, esta indicación semántica elemental también se ofrece en la presentación jerárquica del campo semántico (al inicio de cada campo) y en los mapas conceptuales.
} 


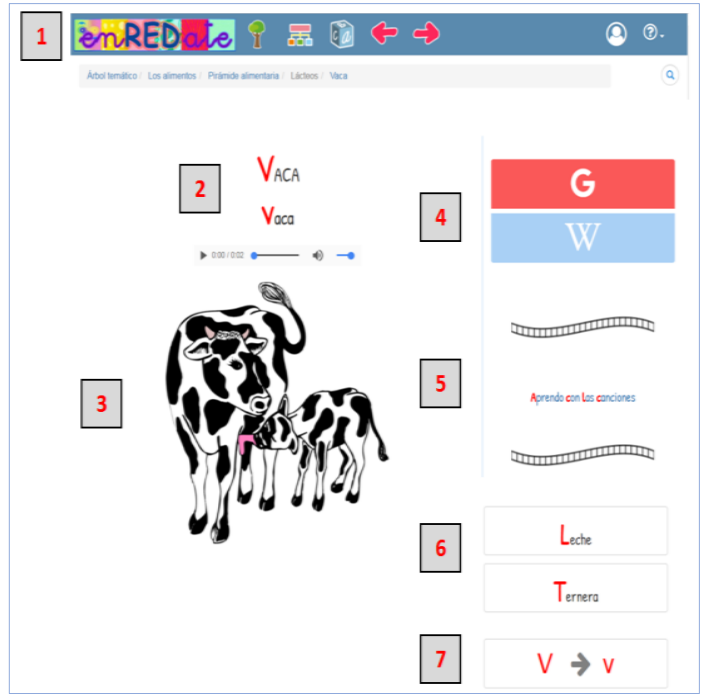

IMAGEN 4. Modelo de artículo lexicográfico

\section{EXPLOTACIÓN DIDÁCTICA: ENSEÑAR Y APRENDER JUGANDO CON ENRÉDATE}

Junto al diccionario en sí, hemos confeccionado un amplio catálogo de actividades para que tanto el profesorado como el alumnado pueda aprovechar su potencial didáctico ${ }^{18}$. Igualmente, otro objetivo es desarrollar en los estudiantes la "competencia lexicográfica", es decir, el conocimiento, uso y aprovechamiento de todo el potencial informativo del diccionario, así como animarlos a emplear asiduamente estas herramientas didácticas, esenciales para el aprendizaje y uso del idioma.

Pretendemos que las actividades les resulten divertidas, despierten su curiosidad y su deseo de aprender, por lo que el componente lúdico es la base sobre la que se sustenta nuestra propuesta de explotación didáctica.

\subsection{EL COMPONENTE LÚDICO EN EDUCACIÓN}

En la bibliografía sobre este tema se aprecian ciertas discrepancias entre los términos "gamificación", "ludificación” y "Aprendizaje Basado en el Juego" (Game Based Learning, GBL), y podemos encontrar un amplio número de definiciones y caracterizaciones (Area y González, 2015; Deterding et al., 2011; Kapp, 2012; Molina

18 Para ello nos hemos basado en ideas, orientaciones, teorías, tipologías y actividades propuestas por diversos autores: Alvar (2001, 2003), Baralo (1997, 2001, 2005, 2006, 2007), Calero (1992), Carvajal et al. (2014), Cassany, Luna y Sanz (2003), Cervero y Pichardo (2000), Estaire (2007), García Cámara (2017), Higueras (2008, 2009), Iglesias y Prieto (2007), Jorge Rodríguez (2011), Lüning (1996), Maldonado (1998), Moreno et al. (2013), Prado (2001, 2005, 2009), Tejero (1999). 
et al., 2017; Rojas, 2017; Zichermann \& Cunningham, 2011; Zichermann \& Linder, 2013). La diferenciación de dichos términos excede los objetivos de este trabajo, por lo que, siendo conscientes de estas discrepancias en el plano denominativo, al referimos al componente lúdico en la educación remitimos a características comunes que presentan dichas denominaciones, como el empleo de estrategias, dinámicas y diversos elementos propios de los juegos en otros contextos que no son el ocio y el tiempo libre, con el objetivo de transmitir unos contenidos y desarrollar unas destrezas mediante una experiencia lúdica que potencia la motivación y la diversión del alumnado.

Además de lo señalado, y como señala Rojas (2017: 695-696), el juego en clase potencia otros aspectos esenciales como el desarrollo de habilidades sociales tales como el compañerismo, el respeto, la empatía..., convierte actividades y ejercicios potencialmente aburridos en interesantes $y$, por lo tanto, motivadores; facilita actividades difíciles, estimula la comunicación entre el alumnado, y entre este y el profesor, y promueve tanto la participación constante como el esfuerzo.

En la tradición educativa, el juego siempre ha sido un elemento muy considerado. De este modo, si acudimos a grandes referentes en el terreno de la educación, ya Vigotsky (1979 y 1988) lo considera un factor básico de desarrollo intelectual desde lo social. El juego está relacionado con el placer, y al mismo tiempo que juega, el niño se somete a ciertas reglas. De este modo, se crea una zona de desarrollo próximo, resultando esta actividad un marco facilitador para cambios evolutivos.

Igualmente, Bruner (1984) plantea funciones fundamentales del juego infantil, ya que es una actividad extremadamente importante para que el desarrollo de los niños. Aunque se planteen actividades serias, no tiene consecuencias frustrantes, ya que el niño los afronta como una exploración. Este autor también plantea su relación con el lenguaje y el pensamiento, puesto que el juego favorece el desarrollo simbólico y la creatividad, es una proyección del mundo interior y se relaciona con el aprendizaje: jugando se interioriza el mundo externo hasta llegar a hacerlo parte de uno mismo.

Por tanto, el empleo de dinámicas lúdicas en entornos educativos no es algo nuevo, pero en la actualidad, la posibilidad de disponer de medios técnicos posibilita una 


\section{EL LÉXICO EN EL AULA DE EDUCACIÓN INFANTIL Y PRIMARIA: \\ ENSEÑA Y APRENDE JUGANDO CON ENRÉDATE \\ Narciso M. Contreras Izquierdo}

explotación mucho mayor de estos recursos, modificando la forma de enseñar y aprender:

desde tiempos inmemoriales ha quedado patente que el ser humano aprende jugando. Sin embargo, la tecnología y los avances científicos nos dan la oportunidad de introducir elementos innovadores en las aulas, los cuales nos ayudan a modificar nuestra metodología docente, y por ello, tener como objetivo el desarrollo del aprendizaje significativo (Molina et al., 2017: 1-2).

Además, estudios como el de Hamari, Koivisto y Sarsa (2014) demuestran que las estrategias y técnicas lúdicas en el ámbito educativo ofrecen resultados positivos, al reforzar la motivación del alumnado para la ejecución de actividades, lográndose así una mejor consecución de los objetivos pedagógicos planteados. En todas las etapas educativas, y más en las que nos centramos aquí, el juego permite a los docentes el trabajo de los contenidos y el desarrollo de habilidades de forma motivadora, además del desarrollo de la creatividad, la imaginación, favoreciendo al mismo tiempo la comunicación entre el alumnado, su cohesión y la integración grupal.

Como vemos, la motivación es uno de los aspectos más destacados en muchos de los estudios que analizan el impacto de lo lúdico en educación ${ }^{19}$, aunque las investigaciones ponen de manifiesto que son más los factores a destacar en la mejora del aprendizaje de los alumnos. En este sentido, Molina et al. (2017: 19) mencionan la diversión, la autonomía, la progresividad, la retroalimentación, la experimentación y la creatividad.

Mas concretamente, Tornero (2009: 5-12) presenta y comenta muchos de los beneficios que las actividades lúdicas aportan en el aprendizaje de lenguas, resaltando nosotros, entre otras, las siguientes:

1. Efecto desinhibidor. Con el juego se genera un ambiente distendido que ayuda a que los alumnos más introvertidos no se sientan incómodos ni intimidados en clase.

\footnotetext{
${ }^{19}$ Según Lee y Hammer (2011), los juegos son motivadores debido a su impacto en las áreas cognitivas, emocionales y sociales de los participantes. Por otro lado, y también en relación con la motivación, Romero et al. (2017: 112) señalan que la gamificación en la educación "podría traducirse como un método de enseñanza por contrabando: aprender sin percatarse de que se está aprendiendo".
} 
2. Estímulo cognitivo. En el juego se requiere un mayor esfuerzo intelectual por parte de los alumnos, ya que agudiza el ingenio, la astucia y la imaginación. Además, en el juego son necesarias la negociación, la cooperación, la resolución de conflictos, el análisis de diversas situaciones y contextos... lo que propicia y posibilita un mayor desarrollo cognitivo.

3. Promueve las relaciones sociales. Mediante el juego se crea un clima adecuado que facilita las relaciones interpersonales y grupales, tanto entre los compañeros como también entre estos y el docente. El juego provoca una necesidad real de comunicación entre los estudiantes, por lo que al mismo tiempo pueden emplear los contenidos lingüísticos o culturales trabajados.

4. Potencia la creatividad y el aprendizaje significativo. Como sabemos, la parte izquierda del cerebro se relaciona con el pensamiento lógico, mientras que en la derecha reside la creatividad, lo simbólico, la imaginación y la afectividad. El juego puede ayudar a la búsqueda del equilibrio entre los dos hemisferios, algo determinante si tenemos en cuenta que en el aprendizaje de lenguas intervienen los dos canales: los afectivos y los cognitivos, por lo que la interrelación de ambos mejora el rendimiento de los alumnos.

5. Favorece la participación. Cuando los grupos son numerosos, es difícil la participación activa de todos los alumnos, por lo que en estos casos el juego permite que puedan hacerlo, gracias a la cooperación entre ellos.

6. Reflexión del aprendizaje. Con el juego se posibilita la verificación y el comentario en gran grupo, permitiendo la reflexión del aprendizaje de los alumnos. De este modo, el discente cobra un papel importante en su propio aprendizaje.

Finalmente, no podemos dejar de mencionar la importancia del "juego lingüístico", que también forma parte de nuestra explotacion didáctica, y que lo constituyen

aquellas actividades lingüísticas cuya finalidad no es la comunicación, sino, simplemente, divertirse con la lengua, utilizándolo como objeto de observación, de manipulación, de transgresión y de placer. Entran en esta categoría los trabalenguas, los pareados y las rimas, las adivinanzas y los refranes, la recitación y la memorización de poemas (Bigas, 2008: 62). 


\subsection{TÍPOLOGÍA Y DinÁMICA DE LAS ACTIVIDADES}

El diccionario enRÉDate permite trabajar diversos aspectos, tanto lingüísticos como extralingüísticos: orden alfabético, ortografía, pronunciación, acentuación, género, fraseología, contenidos culturales, etc., con la intención de desarrollar las redes del lexicón mental de los alumnos, y así su competencia léxica y, por ende, su destreza comunicativa, mediante una metodología lúdica, y desde una perspectiva enactiva.

En las actividades que proponemos no se ha precisado el ciclo o curso, ya que muchas de ellas pueden emplearse en distintos niveles, siendo posible modificar lo que sea necesario para adaptarlas a las necesidades o intereses del profesor y de los alumnos.

Como podemos ver, hemos agrupado las actividiades en nueve grandes campos, tantos como aspectos permite practicar la obra:

1. ORDEN ALFABÉTICO:

1.1. Une palabra e imagen y ordena

1.2. Encuentra la imagen mal ordenada

1.3. Completa y ordena

1.4. Añade las letras que faltan y ordena

1.5. Busca en el diccionario la palabra del medio

1.6. "El gato de la maestra es/está + adjetivo"

2. ORTOGRAFÍA

2.1. Completar con "gu" o "gü"

2.2. Completar con "g" o "j"

2.3. Completar con "b" o "v"

2.4. Sopa de letras de palabras con $\mathrm{h}$

2.5. Completar con "c", "z" o "qu"

2.6. Completar con " $r$ " o " $r r$ "

2.7. Crucigrama de palabras con " $\mathrm{x}$ " $\mathrm{y}$ " $\mathrm{s}$ "

2.8. "Las sílabas locas"

3. PRONUNCIACIÓN

3.1. “¿Sabes pronunciar bien en español?”

3.2. Acentuación

4. GÉNERO

4.1. Masculino o femenino

4.2. Juega al "S+7"

5. CAMPOS TEMÁTICOS

5.1. Asociogramas

5.2. Diagramas

5.3. Árboles conceptuales
5.4. Árbol genealógico

5.5. Escalas y gradaciones

5.6. "Respuesta física total"

5.7. Repaso de campos semánticos

5.8. "Crea una historia"

5.9. "Nos vamos al mercado"

5.10. "Intrusos"

5.11. El juego de las categorías

5.12. "Juguemos a adivinar"

5.13. "Adivina adivinanza"

5.14. Ampliación de frases

5.15. Descifrar mensajes en clave

5.16. Cadenas de palabras

5.17. Bingo de palabras

5.18. Juego de mímica

5.19. Sopas de letras y crucigramas

5.20. Definición

5.21. "¿Quién hace qué?"

5.22. Puzle de palabras

5.23. Greguerías

5.24. Construimos palabras

5.25. Coleccionamos palabras

5.26. Pegamos palabras

6. SINÓNIMOS, ANTÓNIMOS, HOMÓNIMOS...

6.1. Une con flechas los opuestos

6.2. Une con flechas palabras sinónimas

6.3. Partido de antónimos 
7. Frases, LOCUCIONES, COLOCACIONES, REFRANES...

8. ¿SABÍAS QUÉ?

8.1. El sonido de los animales

8.2. ¿Verdadero o falso?

8.3. ¿Sabes comportarte?
9. APRENDEMOS CON CUENTOS, CANCIONES, POESÍAS...

9.1. Cuentos: "La ratita presumida"

9.2. Canciones: "La vaca lechera"; "Los vegetales"; "Las partes del cuerpo"

9.3. Poesías

En cuanto a las dinámicas para la realización de estas actividades, además de las indicaciones y recomendaciones que incluimos en los enunciados de las mismas, de forma general, y siempre que el docente lo estime oportuno (por la edad del discente, en actividades y campos más complicados...), se recomienda ayudar a los alumnos a completar las actividades con el estímulo visual que proporciona la imagen que aparece en enRÉDate (todas las imágenes incluidas en la explotación didáctica son enlaces activos a la entrada correspondiente), aprovechando así el potencial cognitivo y didáctico del código dual.

Igualmente, para la evaluación de las actividades, y como retroalimentación para los alumnos, se puede pedir que comprueben entre todos la validez de los resultados, animando para ello a la consulta del diccionario mediante los enlaces activos de las imágenes.

Por lo que se refiere al tipo de agrupación, la mayoría de las actividades están diseñadas para trabajar en parejas o en grupos, posibilitando de este modo el trabajo colaborativo y el andamiaje, lo que a su vez facilitará y potenciará la interacción comunicativa entre los alumnos, así como el aprendizaje significativo.

Finalmente, estimamos que puede ser productivo, en función de la naturaleza del grupo escolar, proponer la realización de las actividades en forma de competición, concediendo puntos por cada una completada correctamente, así como un premio final al grupo que obtenga la mayor puntuación. 


\section{CONCLUSIONES}

La competencia en comunicación lingüística (CCL) contribuye decisivamente al desarrollo cognitivo, social y educativo en las primeras etapas formativas, y dentro de dicha competencia, el componente léxico constituye un componente determinante, pues forma la base de cualquier enunciado.

En este sentido, el diccionario representa un material fundamental para la ampliación de la competencia léxica, y por tanto, la competencia comunicativa del alumno. Es por esto por lo que en este trabajo presentamos una novedosa e innovadora herramienta lexicográfica, enRÉDate, un diccionario por imágenes organizado temáticamente para aprender vocabulario de un modo lúdico, diseñado para niños de 0 a 8 años.

Atendiendo a la organización del lexicón mental de los hablantes, en donde las unidades que lo forman se relacionan mediante asociaciones de todo tipo, hemos diseñado una amplia gama de actividades para orientar la explotación didáctica de esta obra en Educación Infantil y Primaria, basándonos en una metodología lúdica, que potencie la motivación del alumno para conseguir un aprendizaje significativo, y desde una perspectiva enactiva.

\section{BIBLIOGRAFÍA}

Adell Segura, J, y Castañeda Quintero, L. (2012). Tecnologías emergentes, ¿pedagogías emergentes?. En J. Hernández Ortega, M. Pennesi Fruscio, D. Sobrino López y A. Vázquez Gutiérrez (Coords.), Tendencias emergentes en educación con TIC, Barcelona: Espiral, pp. 13-32.

Aitchison, J. (1994). Words in the Mind. An Introduction to the Mental Lexicon, Oxford: Blackwell.

Alvar Ezquerra, M. (1993). Función del diccionario en la enseñanza de la lengua. En M. Alvar Ezquerra, La lexicografía descriptiva, Barcelona: Bibliograf, pp. 165-175.

Alvar Ezquerra, M. (2001). Los diccionarios y la enseñanza de la lengua. En C. Ayala Castro (Coord.), Diccionarios y enseñanza, Alcalá de Henares: Servicio de Publicaciones, pp. 13-29.

Alvar Ezquerra, M. (2003): La enseñanza del léxico y el uso del diccionario, Madrid: Arco Libros.

Area, M., y González, C. S. (2015). De la enseñanza con libros de texto al aprendizaje en espacios online gamificados, en Educatio Siglo XXI, 33/3, pp. 15-30. Disponible [en línea]: https://bit.ly/2RGeV1y.

Arnold, J. et al. (2000). La dimensión afectiva en el aprendizaje de idiomas, Cambridge: Cambridge University Press. 


\section{EL LÉXICO EN EL AULA DE EDUCACIÓN INFANTIL Y PRIMARIA: \\ ENSEÑA Y APRENDE JUGANDO CON ENRÉDATE \\ Narciso M. Contreras Izquierdo}

Baralo, M. (1997). La organización del lexicón en lengua extranjera, Revista de Filología Románica, 14/1, pp. $59-71$.

Baralo, M. (2001). El lexicón no nativo y las reglas de la gramática. En V. Salazar y S. Pastor (Eds.), Tendencias y lineas de investigación en adquisición de segundas lenguas, Alicante: Universidad de Alicante, pp. 23-28. Disponible [en línea]: https://goo.gl/kUX1ao.

Baralo, M. (2005). Aspectos de la adquisición del léxico y su aplicación en el aula. En J. M. Izquierdo, O. Juan Lázaro, J. P. de Basterrechea, M. Alonso, A. Mochón, H. Lim y W. Altman (Eds.), Actas de FLAPE. I Congreso internacional: el español, lengua del futuro, Toledo del 20 al 23 de marzo de 2005. Disponible [en línea]: https://bit.ly/2q8dmhC.

Baralo, M. (2006). Cómo crear redes entre palabras en el aula de ELE. En Conferencia presentada al III Encuentro Práctico de Profesores de ELE, Würzburg, 19-20 de mayo de 2006. Disponible [en línea]: https://goo.gl/wcCsN1.

Baralo, M. (2007). Adquisición de palabras: redes semánticas y léxicas. En Actas del Foro de español internacional: Aprender y enseñar léxico. Disponible [en línea]: https://bit.ly/2Iy5m0e.

Bigas, M. (2008). El lenguaje oral en la escuela infantil. En M. Bigas y M. Correig (Eds.), Didáctica de la lengua en la educación infantil, Madrid: Síntesis, pp. 43-70.

Botta, F. (2012). La integracion multisensorial afecta a la memoria de trabajo, en Ciencia Cognitiva, 6/3, pp. 64-67. Disponible [en línea]: https://bit.ly/2GBRwZZ.

Bruner, J. (1984). Acción, pensamiento y lenguaje, Madrid: Alianza.

Cabero Almenara, J. y Llorente Cejudo, Ma .C. (2015). Tecnologías de la Información y la Comunicación (TIC): escenarios formativos y teorías del aprendizaje, en Revista lasallista de investigación, 12/2. pp. 186-193. Disponible [en línea]: https://bit.ly/2FbjXlt.

Calero Heras, J. (1992). Entre palabras: para aprender a manejar el diccionario, Barcelona: Octaedro.

Carvajal, I., Marín, S. y Ortega, J. (2014). El uso del diccionario en el aula de Educación Primara, en Káñina, XXXVIII, pp. 57-63. Disponible [en línea]: https://bit.ly/2r5Wskj.

Cassany, D., Luna, M. y Sanz, G. (2003). Enseñar lengua, Barcelona: Editorial Graó [9a edición].

Cervero, M. ${ }^{a}$ J. y Pichardo, F. (2000). Aprender y enseñar vocabulario, Madrid: Edelsa.

Clark, J. y Paivio, A. (1991). Dual coding theory and education, en Educational Psycology Review, 3, pp. 233262.

Deterding, S., Dixon, D., Khaled, R., y Nacke, L. (2011). From game design elements to gamefulness: defining gamification, en Proceedings of the 15th International Academic MindTrek Conference: Envisioning Future Media Environments, Finland, pp. 9-15.

Estaire, S. (2007). Tareas para reciclar el léxico y ampliar sus redes asociativas, en Actas del Programa de formación para profesorado de Español como Lengua Extranjera 2006-2007, Instituto Cervantes de Múnich. Disponible [en línea]: https://bit.ly/2qczzKv.

García Cámara, M. ${ }^{a}$ S. (2017). Didáctica del vocabulario en Educación Infantil, en Publicaciones Didacticas, 81, pp. 617-623. Disponible [en línea]: https://goo.gl/gAh2MH. 


\section{EL LÉXICO EN EL AULA DE EDUCACIÓN INFANTIL Y PRIMARIA: \\ ENSEÑA Y APRENDE JUGANDO CON ENRÉDATE \\ Narciso M. Contreras Izquierdo}

Gesú, F. di (2016). Modelo mental y modelo social en la construcción de un lexicón en aprendices italianos de Español como lengua segunda. Una perspectiva enactiva. En A. López y D. Jorques (Eds.), Enacción y léxico, Valencia: Tirant Humanidades, pp. 57-69.

Guibourg, I. (2008). El desarrollo de la comunicación. En M. Bigas y M. Correig (Eds.), Didáctica de la lengua en la educación infantil, Madrid: Síntesis, pp. 13-42.

Hamari, J., Koivisto, J. y Sarsa, H. (2014). Does gamification work? A literature review of empirical studies on gamification. En IEEE Computer Society (Ed.), System Sciences (HICSS), pp. 30253034.

Higueras García, M. (2004). Claves prácticas para la enseñanza del léxico, en Carabela, 56, pp. 5-25. Disponible [en línea]: https://bit.ly/2EcBadI.

Higueras García, M. (2008). Vocabulario. De las palabras al texto. A1, Madrid: SM.

Higueras García, M. (2009). Vocabulario. De las palabras al texto. A2, Madrid: SM.

Iglesias Casal, I. y Prieto Grande, Mª (2007). ¡Hagan juego! Actividades y recursos lúdicos para la enseñanza del español, Barcelona: Edinumen [2 Edición].

Johnson, L., Adams Becker, S., Estrada, V. y Freeman, A. (2015). NMC Horizon Report: Edición Educación Superior 2015, Austin, Texas: The New Media Consortium. Versión en español disponible [en línea]: https://bit.ly/1J90QQS].

Jorge Rodríguez, N. A. (2011). La enseñanza del vocabulario: la semántica idiomática en el aula, en Didáctica. Lengua y Literatura, 23, pp. 195-225. Disponible [en línea]: https://goo.gl/ck8As9.

Kapp, K. M. (2012). The Gamification of Learning and Instruction: Game-based Methods and Strategies for Training and Education, New York: John Wiley \& Sons.

Lahuerta Galán, J. y Pujol Vila, M. (1996). El lexicón mental y la enseñanza de vocabulario. En C. Segoviano (Ed.), La enseñanza del léxico español como lengua extranjera, Frankfurt-Madrid: VervuertIberoamericana, pp. 117-129.

Lee, J. J., y Hammer, J. (2011). Gamification in education: what, how, Why Bother? Definitions and uses, en Exchange Organizational Behavior Teaching Journal, 15/2, pp. 1-5.

López García, A., Montaner, A., Morant, R. y Pruñonosa, M. (2011). Redes léxicas como redes neuronales, en Revista de Investigación Lingüistica, 14, pp. 61-86.

Lüning, M. (1996). Aprendizaje creativo del vocabulario. En C. Segoviano (Ed.), La enseñanza del léxico español como lengua extranjera, Frankfurt-Madrid: Vervuert-Iberoamericana, pp. 130-139.

Maldonado González, C. (1998): Uso del diccionario en el aula, Madrid: Arco Libros.

McCarthy, M. (1990): Vocabulary, Oxford: OUP.

Meyer, R. E., y Anderson, R. B. (1992). The instructive animation: Helping students build connections between words and pictures in multimedia learning, en Journal of Educational Psychology, 4, pp. 444452.

Molina Álvarez, J. J., Ortiz Colón. A. M., y Agreda Montoro, M. (2017). Análisis de la integración de procesos gamificados en Educación Primaria. En J. Ruiz Palmero, J. Sánchez Rodríguez, E. Sánchez Rivas (Eds.), Innovación docente y uso de las TIC en educación, Málaga: UMA Editorial, pp. 110 . 


\section{EL LÉXICO EN EL AULA DE EDUCACIÓN INFANTIL Y PRIMARIA: \\ ENSEÑA Y APRENDE JUGANDO CON ENRÉDATE \\ Narciso M. Contreras Izquierdo}

Moreno Moreno, M. ${ }^{a}$ A. (2016a). Espacios para la creatividad. Enrédate. Diccionario temático para niños: proyecto de innovación docente, en Etudes Romanes de Brno, 37/2, pp. 229-246.

Moreno Moreno, M. ${ }^{a}$ A. (2016b). Los diccionarios monolingües del español destinados a los niños: la historia de un educativo subproducto (1787-1920), en Anuario de Estudios Filológicos, XXXIX, pp. 171-196.

Moreno Moreno, M. ${ }^{a}$ A., Contreras Izquierdo, N. M., Torres Martínez, M. y García Fernández, L. (2013). ¿Usamos el diccionario?: Plataforma de autoaprendizaje para lengua Española [CD-ROM], Jaén: Servicio de Publicaciones.

Moreno Moreno, M. ${ }^{a}$ Á., Contreras Izquierdo, N. M., Torres Martínez, M, Camacho Niño, J. y Ruiz Sánchez, I. (2018). enRÉDate. Diccionario temático infantil. Jaén: Seminario de Lexicografía Hispánica. Disponible [en línea]: https://www.enredate.es/.

Moreno Ramos, J. (2004). Enseñar lengua desde un enfoque léxico, en Glosas didácticas. Revista electrónica internacional, 11, pp. 162-168. Disponible [en línea]: https://bit.ly/2FlANxZ.

Nation, I.S.P. (2001). Learning Vocabulary in Another Language, Cambridge: Cambridge University Press.

Orden ECD/65/2015, de 21 de enero, por la que se describen las relaciones entre las competencias, los contenidos y los criterios de evaluación de la educación primaria, la educación secundaria obligatoria y el bachillerato. Boletín Oficial del Estado, núm. 25, de 29 de enero de 2015, pp. 6986-7003. Disponible [en línea]: https://bit.ly/1Y8oPsf.

Orden de 5 de agosto de 2008, por la que se desarrolla el Currículo correspondiente a la Educación Infantil en Andalucía. Boletín Oficial de la Junta de Andalucía, núm. 169, de 26 de agosto de 2008, pp. 17-53.

Paivio, A. (2014). Intelligence, dual coding theory, and the brain, en Intelligence, 47, pp. 141-158.

Pérez Tornero y Pi, M. (2014). Perspectivas 2014: Tecnología y pedagogía en las aulas. El futuro inmediato en España, Universidad Autónoma de Barcelona: aula Planeta. Disponible [en línea]: https://bit.ly/1vrSLmo.

Prado Aragonés, J. (2000). El diccionario y la enseñanza de la lengua. En S. Ruhstaller y J. Prado Aragonés (Eds.), Tendencias en la investigación lexicográfica del español. El diccionario como objeto de estudio lingüístico y didáctico, Huelva: Universidad, pp. 171-192.

Prado Aragonés, J. (2001). El diccionario como recurso para la enseñanza del léxico: estrategias y actividades para su aprovechamiento. En C. Ayala Castro (Coord.), Diccionarios y enseñanz̨a, Alcalá de Henares: Servicio de Publicaciones, pp. 209-226.

Prado Aragonés, J. (2005). Estrategias y actividades para el uso diccionario en el aula, en Káñina, XXIX, pp. 53-71. Disponible [en línea]: https://goo.gl/U7fuuA.

Prado Aragonés, J. (2005b). El uso del diccionario para la enseñanza de la lengua: consideraciones metodológicas, en Káñina, XXIX, pp. 19-28. Disponible [en línea]: https://bit.ly/2qu4G4S.

Prado Aragonés, J. (2009). El diccionario y su uso en el aula. Estrategias y actividades (2 vols.), Granada: Grupo Editorial Universitario.

Real Decreto 126/2014, de 28 de febrero, por el que se establece el currículo básico de la Educación Primaria. Boletín Oficial del Estado, núm. 52, de 1 de marzo de 2014, pp. 19349-19420. Disponible en línea: https://bit.ly/1hCr15B. 


\section{EL LÉXICO EN EL AULA DE EDUCACIÓN INFANTIL Y PRIMARIA: \\ ENSEÑA Y APRENDE JUGANDO CON ENRÉDATE \\ Narciso M. Contreras Izquierdo}

Rojas Morales, J. M. (2017). Lo ponemos en juego: La Gamificación del aprendizaje, en Publicaciones Didacticas, 81, pp. 692-699.

Román-Mendoza, E. (2018). Aprender a aprender en la era digital. Tecnopedagogía crítica para la enseñanza del español LE/L2, New York: Routledge.

Romero Rodríguez, L. M., Torres Toukoumidis, Á. y Aguaded, I. (2017). Ludificación y educación para la ciudadanía. Revisión de las experiencias significativas, en Educar, 53/1, pp. 109-128.

Tejero Robledo, E. (1999). Didáctica del vocabulario en un taller de lengua y literatura para educación primaria y secundaria, en Didáctica. Lengua y Literatura, 11, pp. 165-214. Disponible [en línea]: https://goo.gl/uxj1HM

Thornbury, S. (2002). How to teach vocabulary, Harlow: Longman.

Tornero, Y. (2009). Las actividades lúdicas en la clase de E/LE. Ventajas e inconvenientes de su puesta en práctica, Madrid: Edinumen.

Unión Europea. Parlamento Europeo y Consejo de la Unión Europea (2006). Recomendaciones del Parlamento Europeo y del Consejo sobre las competencias clave para el aprendizaje permanente, Bruselas: Unión Europea. Disponible [en línea]: https://bit.ly/2PQgYCV

Vigotsky, L. S. (1979): Interacción social, Madrid: Paidós.

Vigotsky, L. S. (1988): El desarrollo de los procesos psicológicos superiores, México: Grijalba.

Wilkins, D. (1972): Linguistics in Language Teaching, Londres: Edward Arnold.

Zichermann, G. y Cunningham, C. (2011). Gamification by Design: Implementing Game Mechanics in Web and Mobile Apps, Massachusetts: O'Reilly Media, Inc.

Zichermann, G. y Linder, J. (2013). The Gamification Revolution: How Leaders Leverage Game Mechanics to Crush the Competition, McGraw Hill Professional. 